\title{
EXCESS THERMO-ACOUSTICAL PARAMETERS IN BINARY LIQUID MIXTURES OF BUTYL ACETATE AND O-ANISIDINE AT FOUR DIFFERENT TEMPERATURES $\mathrm{T}=(\mathbf{3 0 3 . 1 5 , 3 0 8 . 1 5 , 3 1 3 . 1 5}$ and 318.15)K
}

\author{
B. Vijay Kumar ${ }^{1, *}$, Sk. Fakruddin Babavali ${ }^{1}$, K.Narendra ${ }^{1}$ and M.Srilakshmi ${ }^{2}$ \\ ${ }^{1}$ Department of Physics, V.R.Siddhartha Engineering College, Vijayawada (A.P), India \\ ${ }^{1}$ Department of Chemistry, V.R.Siddhartha Engineering College, Vijayawada (A.P), India \\ *E-mail: vijju.phy@gmail.com
}

\begin{abstract}
Ultrasonic speeds $(u)$, densities $(\rho)$, and viscosities $(\eta)$ have been measured in liquid mixtures containing butyl acetate and o-anisidine at different temperatures $\mathrm{T}=(303.15,308.15,313.15$ and 318.15$) \mathrm{K}$ over the entire mole fraction range. From the experimentally measured data, excess thermo-acoustical parameters such as excess internal pressure, excess enthalpy, excess molar volume, and excess acoustic impedance have been calculated. The results are fitted to the Redlich-Kister polynomial equation and they have been explained on the basis of molecular interactions between the components of liquid mixtures.

Keywords: Ultrasonic speed, density, viscosity, internal pressure, enthalpy, excess parameter, butyl acetate and oanisidine.
\end{abstract}

(C) RASĀYAN. All rights reserved

\section{INTRODUCTION}

In understanding the physico-chemical behavior, ultrasonic methods find extensive applications ${ }^{1-9}$.In order to study the intermolecular interactions between component molecules, ultrasonic measurements in liquid mixtures consisting of polar and non-polar components are of considerable importance and they find applications in several industrial and technological processes. Specific interactions in liquid mixtures can be determined from measurements of excess properties and deviations in physical properties. Physical properties are important in industrial applications. Ultrasonic velocity and their derived investigations in liquid mixtures find eminent applications in characterizing physico-chemical behavior and non-ideal behavior $^{10-12}$.In the present work, authors reported the variations of excess thermo acoustical parameters in binary liquid mixtures containing butyl acetate and o-anisidine at different temperatures $\mathrm{T}=(303.15,308.15,313.15$ and 318.15$) \mathrm{K}$ over the entire mole fraction range of o-anisidine. Deviations of these parameters indicate the presence of interactions between the component molecules of the liquid mixtures.

\section{EXPERIMENTAL}

The non-polar solvents O-Anisidine and Butyl Acetate are of Ranbaxy LR grade samples and these were purified by usual methods ${ }^{13-15}$. The ultrasonic velocities of the O-Anisidine and Butyl Acetate were measured using multi-frequency ultrasonic interferometer at a frequency of $3 \mathrm{MHz}$ (Mittal enterprises Model F-80X). The accuracy of measurement of ultrasonic velocity (U) was within $\pm 0.15 \%$. The densities $(\rho)$ of these liquids were measured using $25 \mathrm{ml}$ specific gravity bottle in an electronic balance precisely within $\pm 0.01 \%$ accuracy. An electronic weighing balance (Shimadzu AUY220, Japan), with a precision of + or $-0.1 \mathrm{mg}$ is used for the measurements of mass of pure liquids or liquid mixtures. Ostwald viscometer is used to measure viscosities of the liquids. The accuracy of the apparatus is $0.002 \%$. In all the above apparatus the temperature was maintained constant at $303.15 \mathrm{~K}, 308.15 \mathrm{~K}, 313.15 \mathrm{~K} \&$ $318.15 \mathrm{~K}$ using proportional temperature controller of accuracy $\pm 0.01 \mathrm{~K}$. 


\section{RESULTS AND DISCUSSION}

The comparison of experimentally measured values of densities, ultrasonic velocities and viscosities of pure liquids together with the literature values is given in Table-1. The experimentally measured values of ultrasonic velocities $(u)$, densities $(\rho)$ and viscosities $(\eta)$ over an entire mole fraction range of o-anisidine at temperatures $\mathrm{T}=(303.15,308.15,313.15$ and 318.15$) \mathrm{K}$ are given in the Table- 2 .

Table-1: Values of densities $(\rho)$, ultrasonic velocities $(u)$ and viscosities $(\eta)$ of pure liquids together with literature values at temperature $\mathrm{T}=303.15 \mathrm{~K}$.

\begin{tabular}{c|c|c|c|c|c|c}
\hline \multirow{2}{*}{ Liquid } & \multicolumn{2}{|c|}{$\rho /\left(\mathrm{Kg}^{-3}\right)$} & \multicolumn{2}{c|}{$\mathrm{u} /\left(\mathrm{m}^{-3} \mathrm{~s}^{-1}\right)$} & \multicolumn{2}{c}{$\eta /\left(\mathrm{Ns}^{-2}\right)$} \\
\cline { 2 - 7 } & $\operatorname{Exp}$ & Lit & $\operatorname{Exp}$ & Lit & Exp & Lit \\
\hline Butyl acetate & 871.0 & $871.29^{16}$ & 1176.6 & --- & 0.652 & $0.634^{16}$ \\
\hline o-anisidine & 1087.1 & $1087.07^{17}$ & 1525.3 & $1525.26^{17}$ & 3.1125 & $3.1125^{17}$ \\
\hline
\end{tabular}

The excess thermo-acoustical parameters are useful in understanding the nature of molecular interactions in liquid mixtures ${ }^{18}$.Variations of these excess thermo-acoustical parameters such as excess internal pressure $\left(\pi^{\mathrm{E}}\right)$, excess enthalpy $\left(\mathrm{H}^{\mathrm{E}}\right)$, excess molar volume $\left(\mathrm{V}_{\mathrm{m}}^{\mathrm{E}}\right)$, excess acoustic impedance $\left(\mathrm{Z}^{\mathrm{E}}\right)$ with the mole fractions of o-anisidine at temperatures $\mathrm{T}=(303.15,308.15,313.15$ and 318.15$) \mathrm{K}$ are represented in the figures from Fig.-1 to Fig.-4 respectively.

Table-2: Values of ultrasonic velocities $(u)$, densitites $(\rho)$ and viscosities $(\eta)$ over entire molefraction range of oanisidine at temperatures $\mathrm{T}=(303.15,308.15,313.15$ and 318.15$) \mathrm{K}$.

\begin{tabular}{c|c|c|c|c}
\hline $\begin{array}{c}\text { Molefraction of } \\
\text { quinoline } \\
\left(\mathrm{X}_{1}\right)\end{array}$ & $\mathrm{T}=303.15 \mathrm{~K}$ & $\mathrm{~T}=308.15 \mathrm{~K}$ & $\mathrm{~T}=313.15 \mathrm{~K}$ & $\mathrm{~T}=318.15 \mathrm{~K}$ \\
\cline { 2 - 5 } & 1176.6 & 1160.9 & 1139.4 & 1104.2 \\
\hline 0.0000 & 1222.8 & 1205.6 & 1185.2 & 1151.1 \\
\hline 0.1157 & 1265.3 & 1246.8 & 1227.1 & 1195.6 \\
\hline 0.2274 & 1309.3 & 1289.4 & 1270.3 & 1240.8 \\
\hline 0.3353 & 1351.9 & 1330.4 & 1313.6 & 1286.2 \\
\hline 0.4397 & 1393.6 & 1371.4 & 1356.0 & 1331.1 \\
\hline 0.5407 & 1435.2 & 1412.2 & 1398.1 & 1373.8 \\
\hline 0.6384 & 1474.1 & 1449.6 & 1438.1 & 1415.8 \\
\hline 0.7331 & 1495.6 & 1469.8 & 1459.4 & 1440.0 \\
\hline 0.8248 & 1512.6 & 1487.0 & 1478.0 & 1460.9 \\
\hline 0.9138 & 1525.3 & 1500.0 & 1494.8 & 1481.1 \\
\hline 1.0000 & \multicolumn{5}{|c}{ Density $(\rho) /\left(\mathrm{Kg} . \mathrm{m}^{-3}\right)$} & \\
\hline & 871.0 & 866.8 & 860.1 & 855.9 \\
\hline 0.0000 & 887.5 & 884.1 & 877.9 & 873.7 \\
\hline 0.1157 & 908.5 & 904.5 & 898.5 & 894.1 \\
\hline 0.2274 & 932.1 & 927.9 & 922.0 & 917.1 \\
\hline 0.3353 & 956.0 & 951.2 & 945.1 & 939.6 \\
\hline 0.4397 & 979.3 & 973.5 & 967.2 & 961.1 \\
\hline 0.5407 & 1002.7 & 996.4 & 989.9 & 983.1 \\
\hline 0.6384 & 1025.8 & 1018.9 & 1012.5 & 1005.2 \\
\hline 0.7331 & 1048.1 & 1040.9 & 1034.6 & 1027.0 \\
\hline 0.8248 & 1068.5 & 1061.0 & 1054.9 & 1046.8 \\
\hline 0.9138 & 1087.1 & 1080.0 & 1074.6 & 1066.5 \\
\hline 1.0000 & \multicolumn{5}{|c|}{ viscosity $(\eta) /\left(\mathrm{Ns} . \mathrm{m}^{-2}\right)$} \\
\hline & 0.652 & 0.5956 & 0.5591 & 0.5202 \\
\hline 0.0000 & 0.7372 & 0.6705 & 0.6259 & 0.5758 \\
\hline 0.1157 & \multicolumn{5}{|c}{} \\
\hline
\end{tabular}


RASĀYAN J. Chem.

Vol. 11 | No. 2 |608 - 612 | April - June | 2018

\begin{tabular}{l|l|l|l|l}
\hline 0.2274 & 0.8399 & 0.7680 & 0.7175 & 0.6570 \\
\hline 0.3353 & 0.9717 & 0.8917 & 0.8320 & 0.7576 \\
\hline 0.4397 & 1.1278 & 1.0368 & 0.9667 & 0.8749 \\
\hline 0.5407 & 1.3140 & 1.2127 & 1.1289 & 1.0154 \\
\hline 0.6384 & 1.5364 & 1.4188 & 1.3200 & 1.1811 \\
\hline 0.7331 & 1.8403 & 1.7001 & 1.5752 & 1.3980 \\
\hline 0.8248 & 2.1900 & 2.0308 & 1.8802 & 1.6573 \\
\hline 0.9138 & 2.6166 & 2.4257 & 2.2401 & 1.9630 \\
\hline 1.0000 & 3.1125 & 2.9014 & 2.6834 & 2.3463 \\
\hline
\end{tabular}

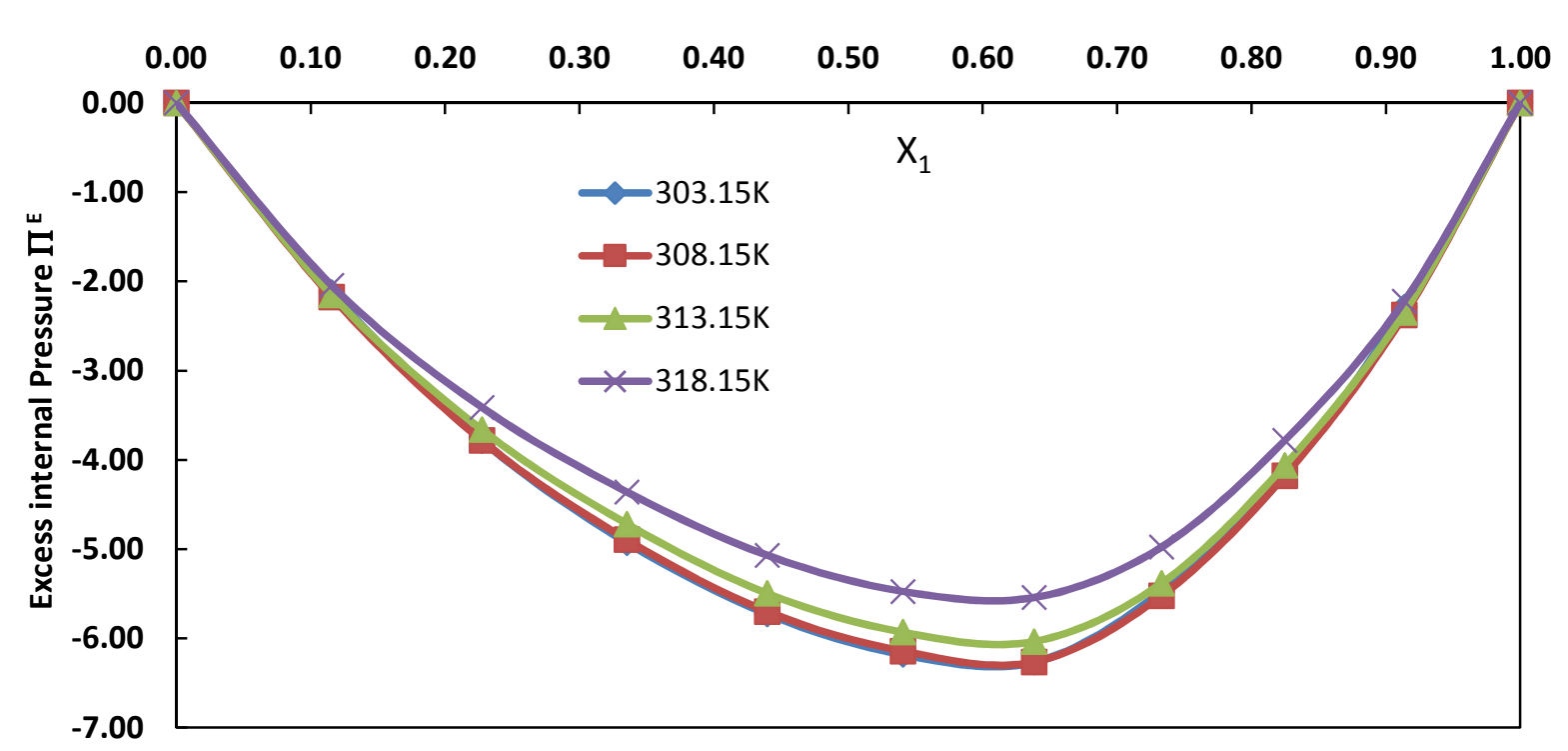

Fig.-1

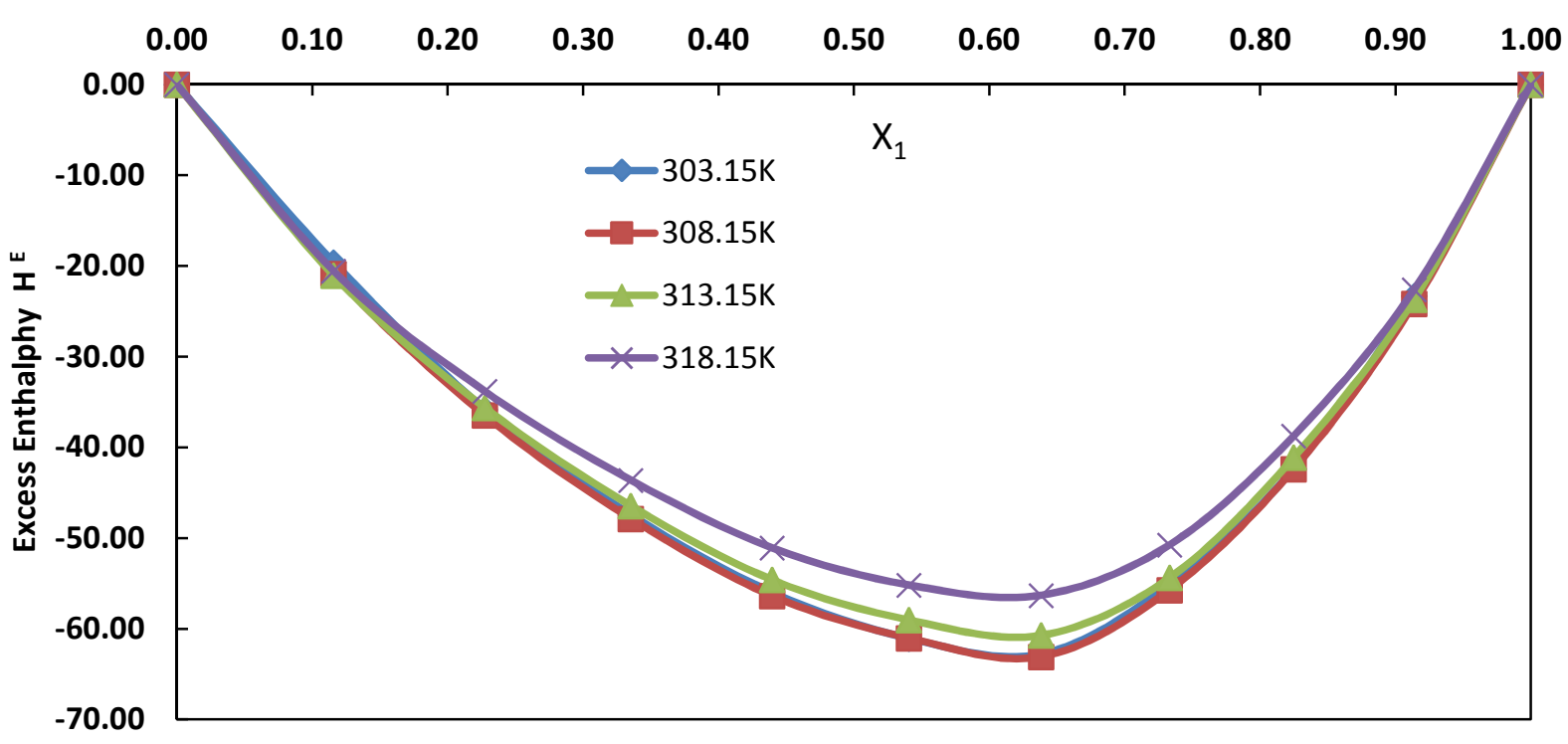

Fig.-2

Figure-1 and 2 indicate the variation of excess internal pressure and enthalpy with an increase in mole fraction of the component O-Anisidine at the temperatures studied. These parameters decrease in the negative axis with an increase in mole fraction of O-Anisidine. They reach minimum values at $\mathrm{x}_{1}=$ 0.4734. Afterward there is an increase in the values of these parameters with further increase of mole fraction of $\mathrm{O}$-Anisidine. The negative deviations of $\pi^{\mathrm{E}}$ and $\mathrm{H}^{\mathrm{E}}$ suggesting weak intermolecular dispersive interaction ${ }^{19}$ between the components $\mathrm{O}$-Anisidine and butyl acetate. 
Figure-3 indicates the variation of the excess molar volume of binary mixtures with an increase in mole fraction of the component O-Anisidine at different temperatures. Further, it is observed that the values of $\mathrm{V}_{\mathrm{m}}{ }^{\mathrm{E}}$ are positive and negative. As the mole fraction of o-anisidine increases above 0.5 , the $\mathrm{V}_{\mathrm{m}}^{\mathrm{E}}$ values are observed to be negative and below this, the values are observed to be positive. The negative values can be visualized as being due to a closer approach of the unlike molecules in the liquid mixtures, thus indicating the existence of specific interactions between the liquid components. Since liquids having significantly different molecular sizes are considered, the $\mathrm{V}_{\mathrm{m}}{ }^{\mathrm{E}}$ values show positive deviations at some places and negative at others.

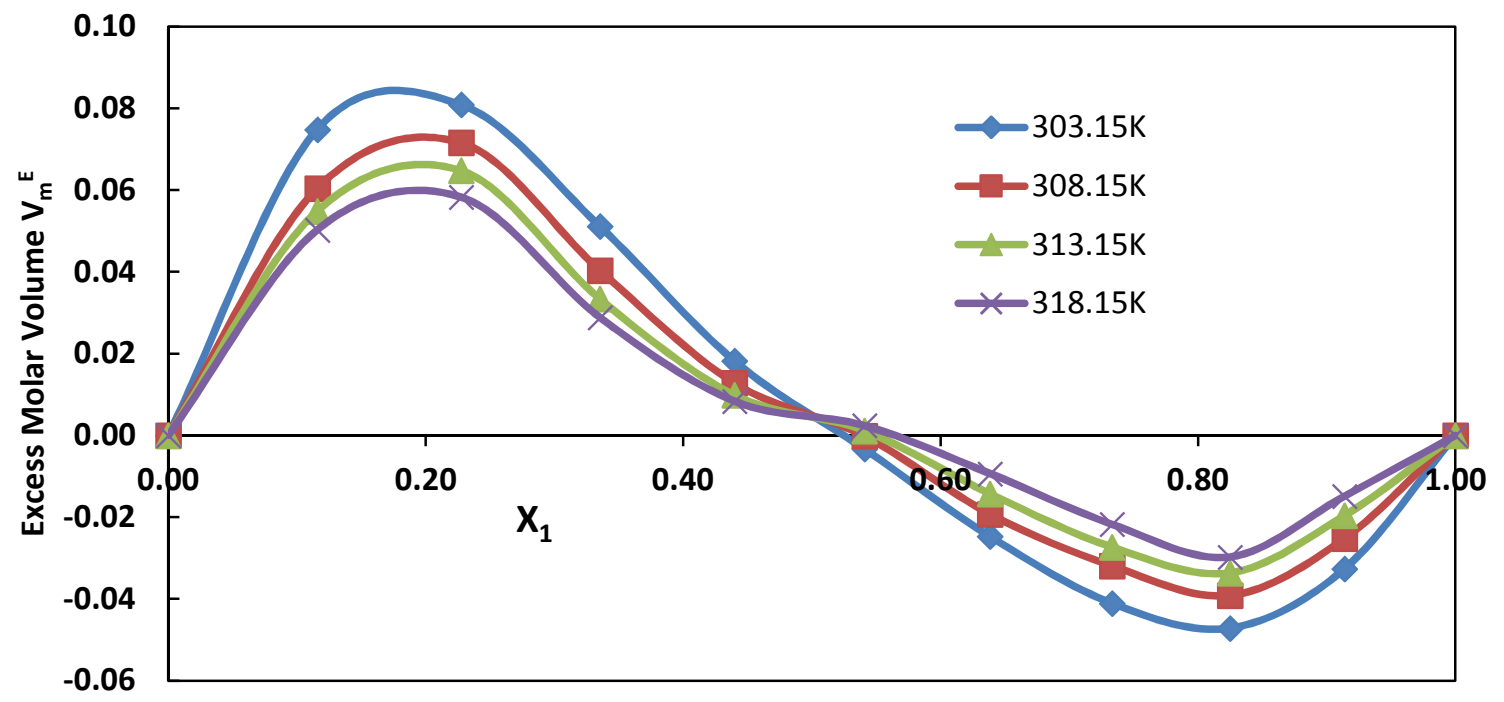

Fig.-3

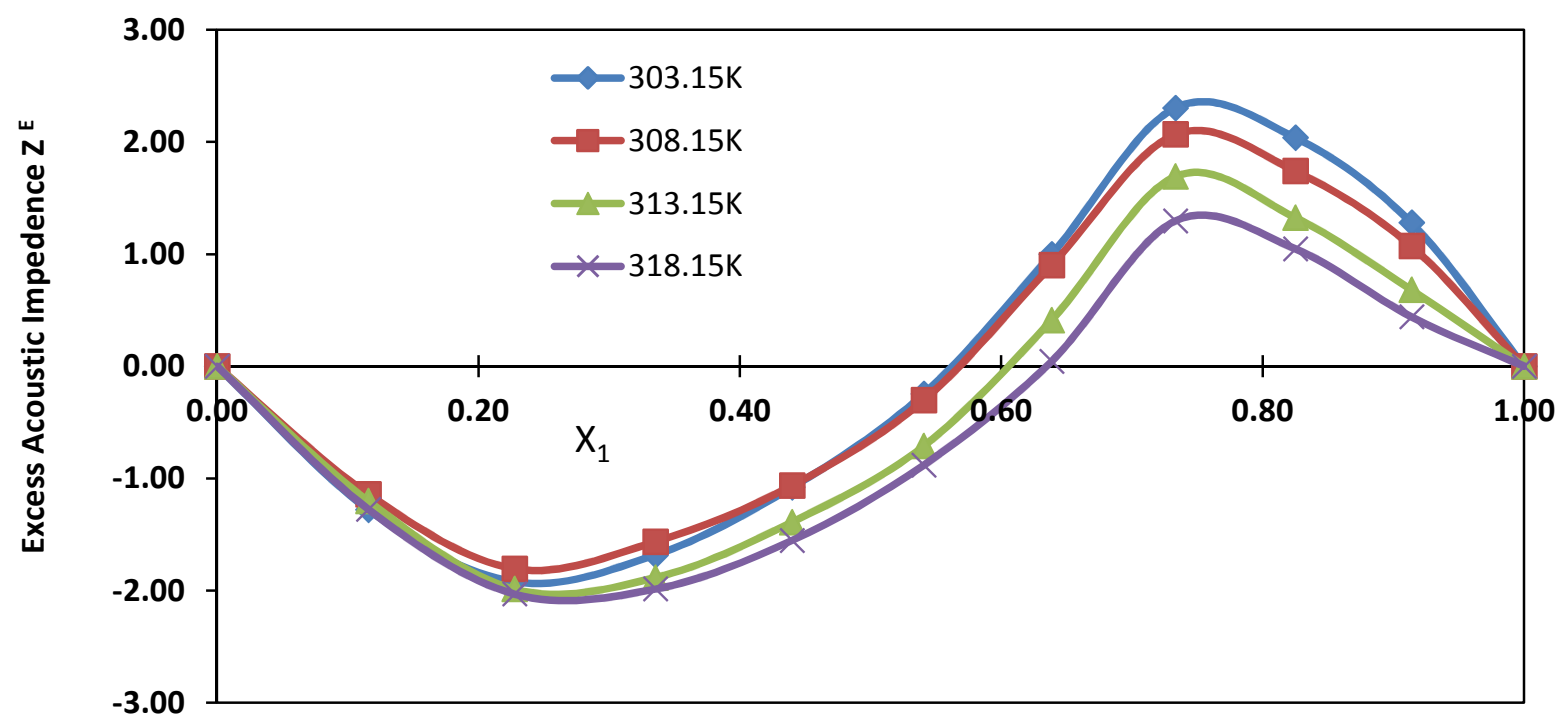

Fig. -4

The variations of excess acoustic impedance with mole fraction of O-Anisidine at different temperature are shown in Fig.-4. From Fig.-4 it is observed that, at lower mole fractions these values are observed to be negative and at higher mole fractions these values are observed to be positive. The positive deviation of $\mathrm{Z}^{\mathrm{E}}$ is attributed to a specific interaction, whereas the negative values suggest weak dipolar interactions ${ }^{19-21}$.

\section{CONCLUSION}

Ultrasonic velocity, density and viscosity values are measured in the binary liquid mixtures containing butyl acetate and $\mathrm{O}$-anisidine at temperatures $\mathrm{T}=(303.15,308.15,313.15$ and 318.15$) \mathrm{K}$. By using these 
values, excess acoustical parameters are obtained over the entire mole fraction range of o-anisidine. An analysis of these results suggests the presence of weak intermolecular interactions in the present binary liquid mixtures.

\section{REFERENCES}

1. S. L. Oswal, V. Pandiyan, B. Krishnakumar, P. Vasantharani, Thermochimica .Acta. 507-508, 27 (2010).

2. K. Narendra, Ch. Srinivasu, Sk. Fakruddin, P. Narayanamurthy, J. Chem. Thermodyn. 43, 1604 (2011).

3. Sk. Fakruddin Babavali , P. Shakira, K. Rambabu, K. Narendra, Ch.Srinivasu, J.Mol..Liq., 220,113 (2016).

4. Sk. Fakruddin Babavali, D. Punyaseshudu, K. Narendra, Ch. Sridhar Yesaswi, Ch. Srinivasu, J.Mol..Liq., 224, 47 (2016).

5. Sk. Fakruddin Babavali, P. Shakira , K. Rambabu , K. Narendra , B. Vijay Kumar, Ch. Srinivasu, Rasayan J. Chem., 9,89 (2016).

6. Sk. Fakruddin Babavali, Ch. Srinivasu, K. Narendra, Ch. Sridhar Yesaswi, Rasayan J. Chem., 9,544 (2016).

7. S. K. Fakruddin, Ch. Srinivasu, K. Narendra, Journal of Chemical and Pharmaceutical Research, 7,488 (2015).

8. S. K. Fakruddin, Ch. Srinivasu, K. Narendra, Journal Chemical and Pharmaceutical Research, 7,491(2015).

9. Sk. Fakruddin, Ch. Srinivasu, Kolla. Narendra, Journal of Chemical and Pharmaceutical Research, 4,3606 (2012)

10. Sk. Fakruddin , Ch. Srinivasu, K. Narendra, Journal of Chemical and Pharmaceutical Research, 4,1799 (2012).

11. Sk Fakruddin Babavali, P. Shakira, K. Rambabu, K. Narendra, Ch. Srinivasu, Research Journal of Pharmaceutical,Biological and Chemical Sciences, 7,1344 (2016).

12. Sk. Fakruddin, K. Narendra, Ch. Srinivasu, Research Journal of Pharmaceutical, Biological and Chemical Sciences, 4,578 (2012).

13. C. V. Suryanarayana, J. Kuppuswamy, J. Acous. Soc. Ind., 4, 75 (1976).

14. C. V. Suryanarayana, Indian J. Chem., 25A, 538 (1986).

15. J. A. Riddick, W. B. Bunger, Organic Solvents: Techniques of Chemistry. 3th ed. Wiley-Interscience: New York; 1970.

16. K. M. Krishanan, K. Rambabu, P. Venkateswarlu, G. K. Raman, J. Chem. Eng. Data., 40,132 (1995).

17. M. Srilakshmi, A. Ratnakar, Ch. Kavitha, K. Narendra, Int. J. Chem. \& Physical Sciences, 3,35 (2014).

18. B. Chandrakant, A. Kumara, A. Singh, Orient. J. Chem., 30,843 (2014).

19. A. Ali, A.Yasmin, A. K. Nain, Indian J. Pure Appl. Phys., 40 ,315 (2002).

20. A. Awasthi, J. P. Shukla, Ultrasonics. 10, 241(2003).

21. R. Meyer, M. Meyer, J. Metzger, A. Peneloux, J. Phys. Chem., 71,1277,(1967).

[RJC-1956/2017] 